\title{
Healthy Photosynthetic Mechanism Suggests ISR Elicited by Bacillus spp. in Capsicum chinense Plants Infected with PepGMV
}

\author{
Blancka Yesenia Samaniego-Gámez ${ }^{1,2, * \mathbb{D}}$, René Garruña ${ }^{3, *}$, José M. Tun-Suárez ${ }^{2}$, Oscar A. Moreno-Valenzuela ${ }^{4}$, \\ Arturo Reyes-Ramírez ${ }^{2}{ }^{\circledR}$, Raúl Enrique Valle-Gough ${ }^{1}{ }^{\circledR}$, Carlos Enrique Ail-Catzim ${ }^{1}$ and Lydia Toscano-Palomar ${ }^{5}$ \\ 1 Institute of Agricultural Sciences, Autonomous University of Baja California, Carretera Blvd, \\ Delta s/n Ejido Nuevo León, Valle de Mexicali, Baja California C.P. 21705, Mexico; \\ raul.valle@uabc.edu.mx (R.E.V.-G.); carlos.ail@uabc.edu.mx (C.E.A.-C.) \\ 2 National Technological Institute of Mexico-Technological Institute of Conkal, Av. Tecnológico s/n, Conkal, \\ Yucatán C.P. 97345, Mexico; jose.tun@itconkal.edu.mx (J.M.T.-S.); arturo.reyes@itconkal.edu.mx (A.R.-R.) \\ 3 CONACYT-Technological Institute of Conkal, Av. Tecnológico s/n, Conkal, Yucatán C.P. 97345, Mexico \\ 4 Scientific Research Center of Yucatan A.C., Department of Plant Biochemistry and Molecular Biology, \\ Calle 43 No. 130, Colonia Chuburná de Hidalgo, Mérida, Yucatán C.P. 97200, Mexico; oamv@cicy.mx \\ 5 National Technological Institute of Mexico-Technological Institute of Mexicali, Av. Instituto Tecnológico s/n, \\ Plutarco Elías Calles, Mexicali, Baja California C.P. 21376, Mexico; toscano.lydia@itmexicali.edu.mx \\ check for \\ updates \\ * Correspondence: samaniego.blancka@uabc.edu.mx (B.Y.S.-G.); renegh10@hotmail.com (R.G.)
}

Citation: Samaniego-Gámez, B.Y.; Garruña, R.; Tun-Suárez, J.M.; Moreno-Valenzuela, O.A.; Reyes-Ramírez, A.; Valle-Gough, R.E.; Ail-Catzim, C.E.; Toscano-Palomar, L. Healthy Photosynthetic Mechanism Suggests ISR Elicited by Bacillus spp. in Capsicum chinense Plants Infected with PepGMV. Pathogens 2021, 10, 455 https://doi.org/10.3390/ pathogens 10040455

Academic Editor:

Paloma Sánchez-Bel

Received: 1 March 2021

Accepted: 6 April 2021

Published: 10 April 2021

Publisher's Note: MDPI stays neutral with regard to jurisdictional claims in published maps and institutional affiliations.

Copyright: () 2021 by the authors. Licensee MDPI, Basel, Switzerland. This article is an open access article distributed under the terms and conditions of the Creative Commons Attribution (CC BY) license (https:// creativecommons.org/licenses/by/ $4.0 /)$.

\begin{abstract}
The aim of this study was to evaluate the effect of inoculation with Bacillus spp. isolates on the photosynthetic apparatus of Capsicum chinense plants infected with PepGMV. In vitro and greenhouse experiments were performed to evaluate whether the inoculation improved plants' performance through the increase in photosynthetic efficiency to control PepGMV. The results showed that despite PepGMV infection, the plants inoculated with some isolates of Bacillus spp. had a healthy photosynthetic mechanism, as the photochemical parameters and gas exchange increased. The maximum photochemical quantum yield of PSII $(\mathrm{Fv} / \mathrm{Fm})$ of plants with PepGMV and inoculated with Bacillus isolates (M9, K46, and K47) increased (7.85, 7.09, and 7.77\%, respectively) with respect to uninoculated controls. In inoculated plants, the $\mathrm{CO}_{2}$ assimilation rate increased and the transpiration rate decreased, therefore indicating an increased water use efficiency. This effect was reflected by the less severe symptoms caused by PepGMV in the plants obtained from seeds inoculated with different Bacillus spp. Plants inoculated with K47 isolates showed an increase in fruit yield and quality. This study suggests that it is possible to protect, at the greenhouse level, C. chinense plants from PepGMV through selected rhizobacteria inoculation.
\end{abstract}

Keywords: chlorophyll fluorescence; gas exchange; geminiviridae; PGPR

\section{Introduction}

Diseases caused by plant pathogenic viruses are common in agricultural crops and cause high economic losses [1]. The genus Begomovirus is the most widespread and diverse worldwide. Pepper golden mosaic virus (PepGMV) is a Begomovirus that is widely distributed in Mexico, where it is considered a major viral pathogen in pepper and other economically important solanaceous crops, such as tomato and tobacco [2]. PepGMV, a bipartite virus, has been reported to be restricted to the vascular tissue, causing bright yellow mosaic symptoms on leaves. These symptoms are associated with the twisting and distortion of leaves and fruits, stunted plants, and reduced yield. PepGMV is transmitted by whiteflies (Bemisia tabaci Gennadius B biotype) [3,4]. Physiological studies have shown that many viral diseases decrease photosynthesis due to their reduction in photosynthetic pigments [5-7]. In addition, Cucumber mosaic virus (CMV) infection caused an alteration in electron transport during photosynthesis and respiration in cucumber and tomato, affecting antioxidant 
systems and leading to oxidative stress in some organelles [7]. Similarly, in apricot cultivars infected with Plum pox virus (PPV), the Photosystem II (PSII) was directly or indirectly affected $[8,9]$. In Nicotiana benthamiana plants infected with tobamoviruses, it was observed that infection reduced the PSII electron transport, affecting the polypeptide composition of the oxygen-evolving complex [10].

Recently there has been an increase in the use of products based on beneficial microorganisms to manage many plant diseases [11,12]. Studies have indicated the importance of different rhizobacteria, such as Azospirillum, Azotobacter, Gluconacetobacter, Pseudomonas, and Bacillus, as alternative tools for biological control and growth promotion [13,14]. Many isolates of Bacillus have been reported as growth promoters, regulating a number of plant physiology parameters. Various properties have been attributed to these bacteria, such as IAA production; $\mathrm{N}_{2}$ fixation; and siderophore production, including schizokinen, phosphate solubilizing, and the secretion of acid phosphatases and phytases [14-18]. Some of these bacteria may also produce different compounds with antagonistic and pathogenic properties, such as extracellular antibiotics-i.e., bacilomycin, iturin, mycosubtilin, and zwittermicin - or lytic enzymes, such as chitinase, protease, and $\beta-1,3$ glucanase. Other properties include the competition for nutrients in the host and Induced Systemic Resistance (ISR), achieved by eliciting the jasmonic acid and ethylene signaling pathways [12,19]. In infections caused by plant viruses, it has been shown that inoculation with Bacillus spp. promotes ISR, favoring a decrease in viral symptoms. This effect is attributed to defense gene expression, decreasing viral replication and thus sustaining plant growth [20].

Most studies on ISR elicited by Bacillus spp. have been directed at the secondary metabolites produced. However, it has been observed that Bacillus spp. could catalyze physiological changes in plants that have not yet been fully investigated [21,22]. Some authors [23,24] studied the effect of Bacillus spp. on the photosynthetic system of Capsicum chinense (Habanero pepper), and others showed that Bacillus spp. inoculation improved the photosystem II efficiency and enhanced photosynthesis in pepper plants [25]. In this sense, we hypothesized that inoculation with Bacillus spp. in pepper plants infected with viruses would sustain photosynthesis and thus yield. Therefore, the aim of this study was to evaluate the effect of inoculation with Bacillus spp. on the photosynthetic apparatus of $C$. chinense plants infected with PepGMV.

\section{Results}

\subsection{Infectivity, Viral Detection and Symptoms Severity}

Both in the growing room and in the greenhouse, the plants obtained from seeds inoculated with Bacillus isolates showed a lower severity of symptoms caused by PepGMV during the entire course of the experiment, indicating some tolerance to the virus (Table 1). PepGMV was detected by PCR amplification in all plants infected with biolistics, whereas it was not detected in control plants (bombarded only with gold particles, without the virus) (Table 1). At $9 \mathrm{dpi}$, an attenuation of symptoms was observed in plants inoculated with Bacillus isolates. Plants that were not inoculated were statistically similar to those inoculated with K46 in severity, but different from those inoculated with M9 and K47 and the untreated control. However, at 15 dpi the plants inoculated with M9, K46, and K47 isolates had a statistically higher severity than the control, but a lower one than that of PepGMV-inoculated plants (Table 1). 
Table 1. Infectivity, viral detection, and severity in pepper plants inoculated with Bacillus. spp. isolates K47, K46, M9, and PepGMV-infected plants; plants with PepGMV only; and control plants (bacteria not inoculated and PepGMV not infected). Different letters represent statistically significant differences (Tukey, $\alpha=0.05, n=5$ ).

\begin{tabular}{cccccc}
\hline \multirow{2}{*}{ Treatments } & \multirow{2}{*}{ PCR Detection } & Infected/Bombarded & \multicolumn{3}{c}{ Severity Scale } \\
\cline { 4 - 6 } & & & $\mathbf{9} \mathbf{d p i}$ & $\mathbf{1 5} \mathbf{d p i}$ & $\mathbf{2 0 0} \mathbf{d p i}$ \\
\hline K47 + PepGMV & + & $5 / 5$ & $0.2^{\mathrm{b}}$ & $1.2^{\mathrm{b}}$ & $1.3^{\mathrm{b}}$ \\
K46 + PepGMV & + & $5 / 5$ & $0.6^{\mathrm{a}, \mathrm{b}}$ & $1.1^{\mathrm{b}}$ & $4.5^{\mathrm{a}}$ \\
M9 + PepGMV & + & $5 / 5$ & $0.2^{\mathrm{b}}$ & $1.1^{\mathrm{b}}$ & $3.1^{\mathrm{a}}$ \\
Control & - & $0 / 0$ & $0.0^{\mathrm{b}}$ & $0.0^{\mathrm{c}}$ & $0.0^{\mathrm{b}}$ \\
PepGMV & + & $5 / 5$ & $1^{\mathrm{a}}$ & $2.5^{\mathrm{a}}$ & $4.8^{\mathrm{a}}$ \\
\hline
\end{tabular}

Both at 9 and $15 \mathrm{dpi}$, plants infected with PepGMV had some moderate yellow mosaic, wrinkle symptoms, deformation of leaves, and dwarfing (Figure 1). Subsequently, the plants were transferred to a greenhouse under controlled conditions. At $200 \mathrm{dpi}$ in the greenhouse, symptoms of light golden mosaics and some deformation of leaves in plants with Bacillus spp. isolates K47, K46, and M9 were observed (Figure 1C,F,I). The plants infected with PepGMV without Bacillus spp. were more affected than those inoculated with the Bacillus isolates (Figure 1O). The control plants, without viruses or rhizobacteria, did not show symptoms (Figure 1L). No symptom was observed during the experimental course (Figure 1J,K,L).

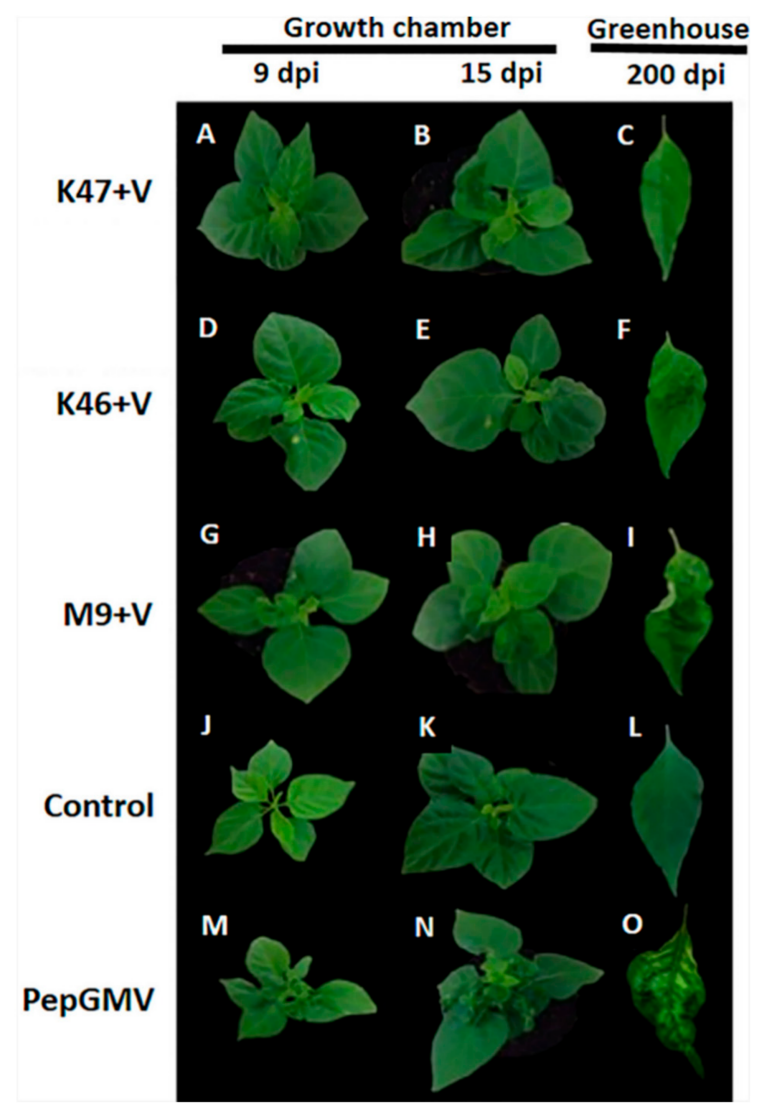

Figure 1. Effect of pepper inoculation with Bacillus subtilis isolates K47, Bacillus cereus spp. isolates K46, Bacillus spp. isolates M9, and infection with PepGMV at $9(\mathbf{A}, \mathbf{D}, \mathbf{G}), 15(\mathbf{B}, \mathbf{E}, \mathbf{H})$, and $200(\mathbf{C}, \mathbf{F}, \mathbf{I})$ days post-infection (dpi). Effect of PepGMV infection alone at 9 (M), 15 (N), and 200 (O) dpi. Control plants (bacteria not inoculated and no PepGMV infection) at 9 (J), 15 (K), and 200 (L) dpi. $n=30$. 


\subsection{Physiological Responses}

The electron transport rate of photosystem II (ETR PSII $\left._{1}\right)$ decreased in plants with PepGMV (non-inoculated with the Bacillus spp.) with respect to the control plants, but ETR $_{\text {PSII }}$ increased in all treatments with Bacillus spp. isolates to increase the photosynthetic

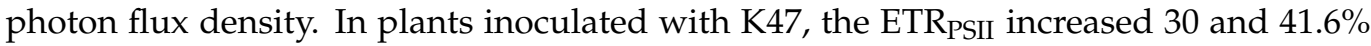
with respect to the control and plants infected with PepGMV, respectively (Figure 2A). The effective photochemical quantum yield of PSII $\left(\Phi_{\mathrm{PSII}}\right)$ was statistically higher in plants inoculated with the Bacillus isolates (K47, M9, and K46). Plants infected with PepGMV without the inoculation of bacteria had lower values of photosynthetic photon flux density (Figure 2B).

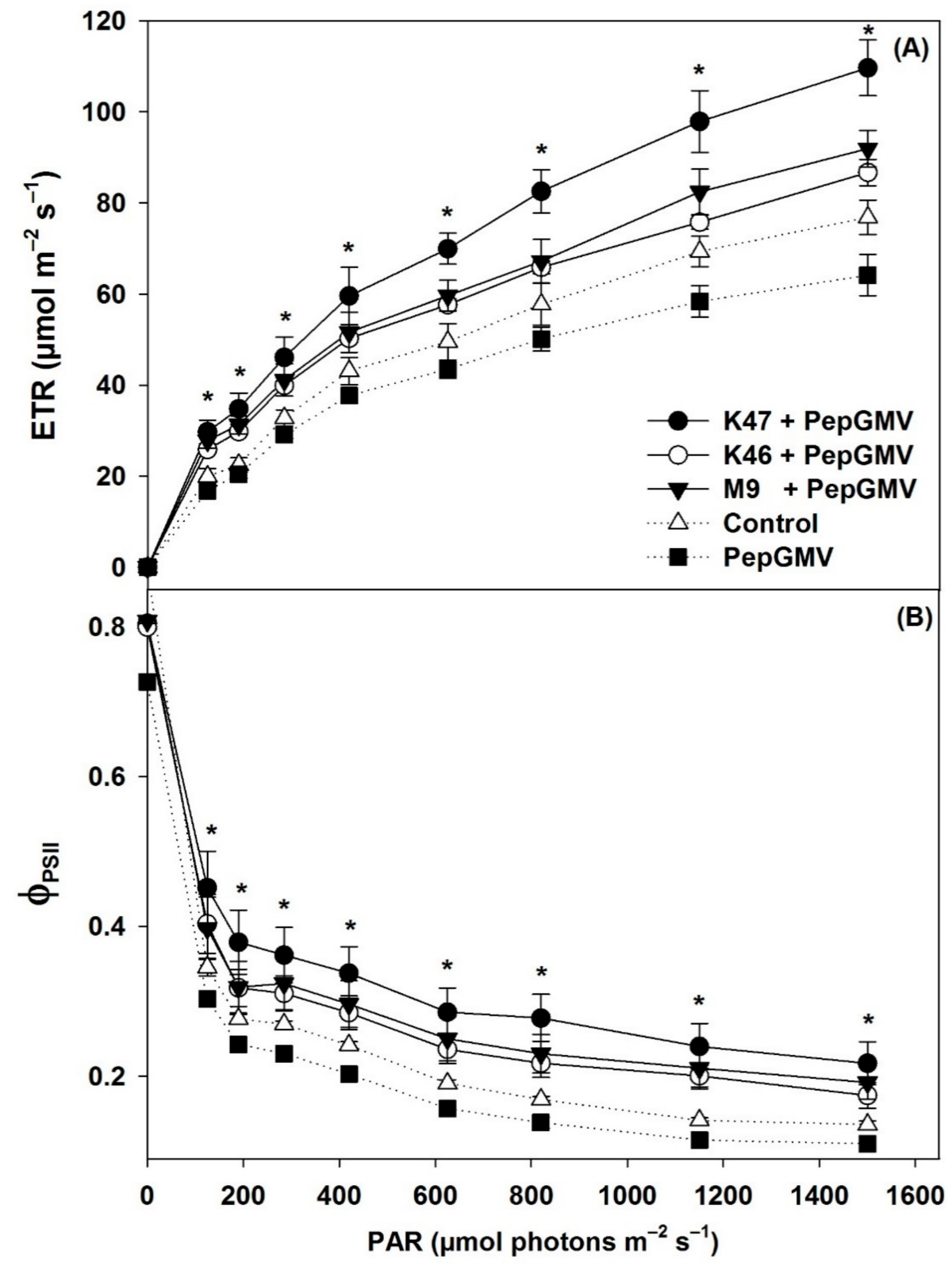

Figure 2. Response curves of electron transport rate (A) and effective photochemical quantum yield (B) of photosystem II to photosynthetic photon flux density in Capsicum chinense plants infected with PepGMV and inoculated with Bacillus subtilis K47, B. cereus K46, Bacillus spp. M9; and plants infected with PepGMV not inoculated. Control = plants not inoculated and not infected. Data are means \pm SE. * = statistically significant (ANOVA, $p \leq 0.05, n=30$ ). 
The ratio of variable to maximum fluorescence or maximum photochemical quantum yield of PSII $\left(\mathrm{F}_{\mathrm{v}} / \mathrm{F}_{\mathrm{m}}\right)$ was statistically higher (ANOVA, $\left.p \leq 0.05\right)$ in plants inoculated with M9, K46, and K47 in 7.85, 7.09, and 7.77\%, respectively, than in PepGMV-infected plants (Figure $3 \mathrm{~A})$. The potential activity of PSII $\left(\mathrm{F}_{\mathrm{v}} / \mathrm{F}_{0}\right)$ showed a statistically similar trend to $\mathrm{F}_{\mathrm{v}} / \mathrm{F}_{\mathrm{m}}$. Values for plants inoculated with M9 and K47 isolates were 16.76 and 16.05\% higher than for PepGMV-infected plants, but the control plants were statistically similar to those inoculated with the Bacillus isolates (Figure 3B).

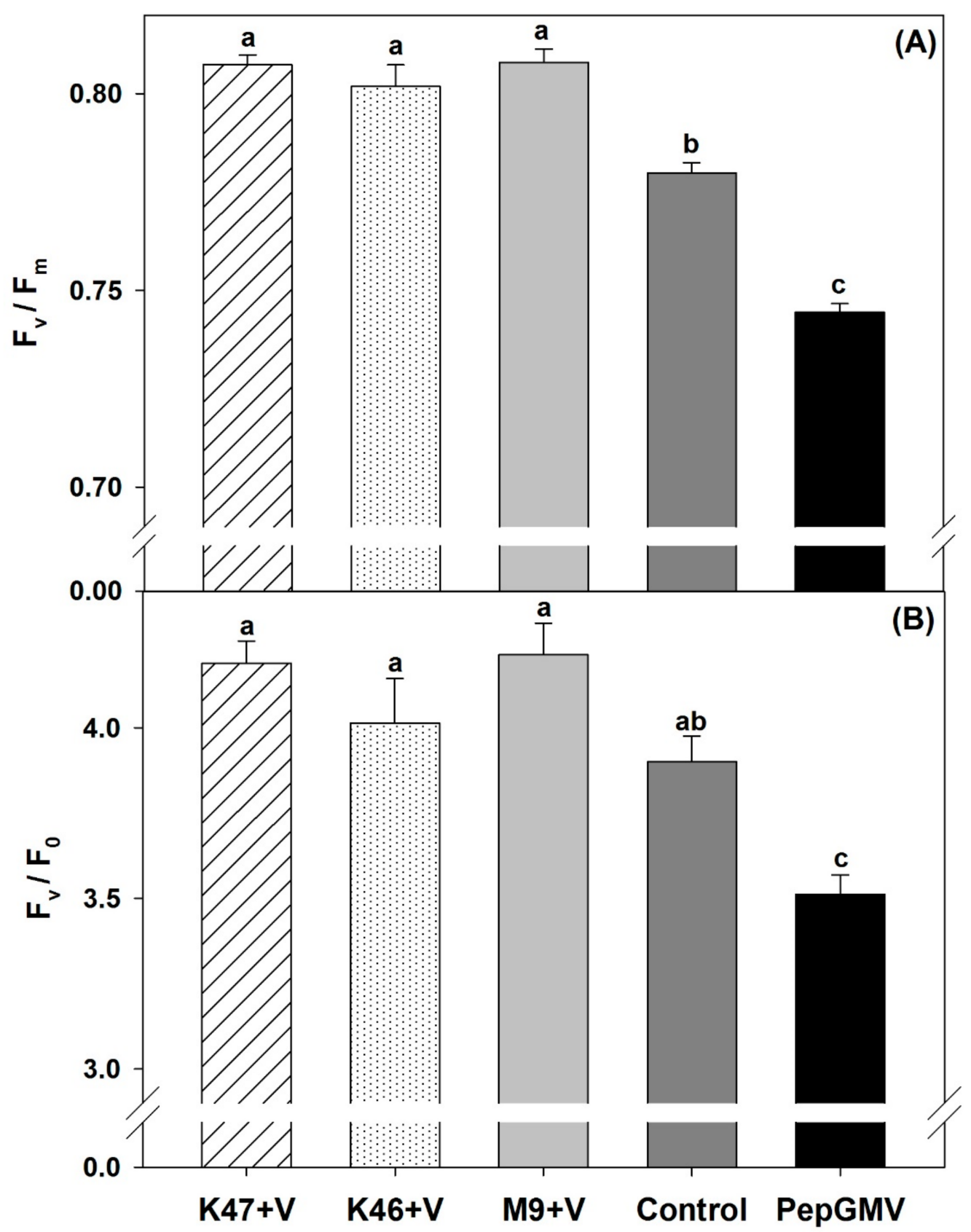

Figure 3. Maximum photochemical quantum yield (A) and potential activity (B) of PSII in Capsicum chinense plants infected with PepGMV and inoculated with Bacillus subtilis K47, B. cereus K46, Bacillus spp. M9; and plants infected with PepGMV not inoculated. Control are plants not inoculated and not infected. All plants inoculated with bacteria were infected with PepGMV. Data are means \pm SE. Different letters represent statistically significant differences (Tukey, $\alpha=0.05, n=30$ ). 
Plants inoculated with M9, K47, and K46 isolates had a statistically higher coefficient of photochemical quenching (qP) than the control and PepGMV-infected plants (Figure 4A). Additionally, non-photochemical quenching (NPQ) showed a statistically similar trend to the coefficient of photochemical quenching $(\mathrm{qP})$, but the control plants were statistically similar to those inoculated with the Bacillus isolates (Figure 4B).

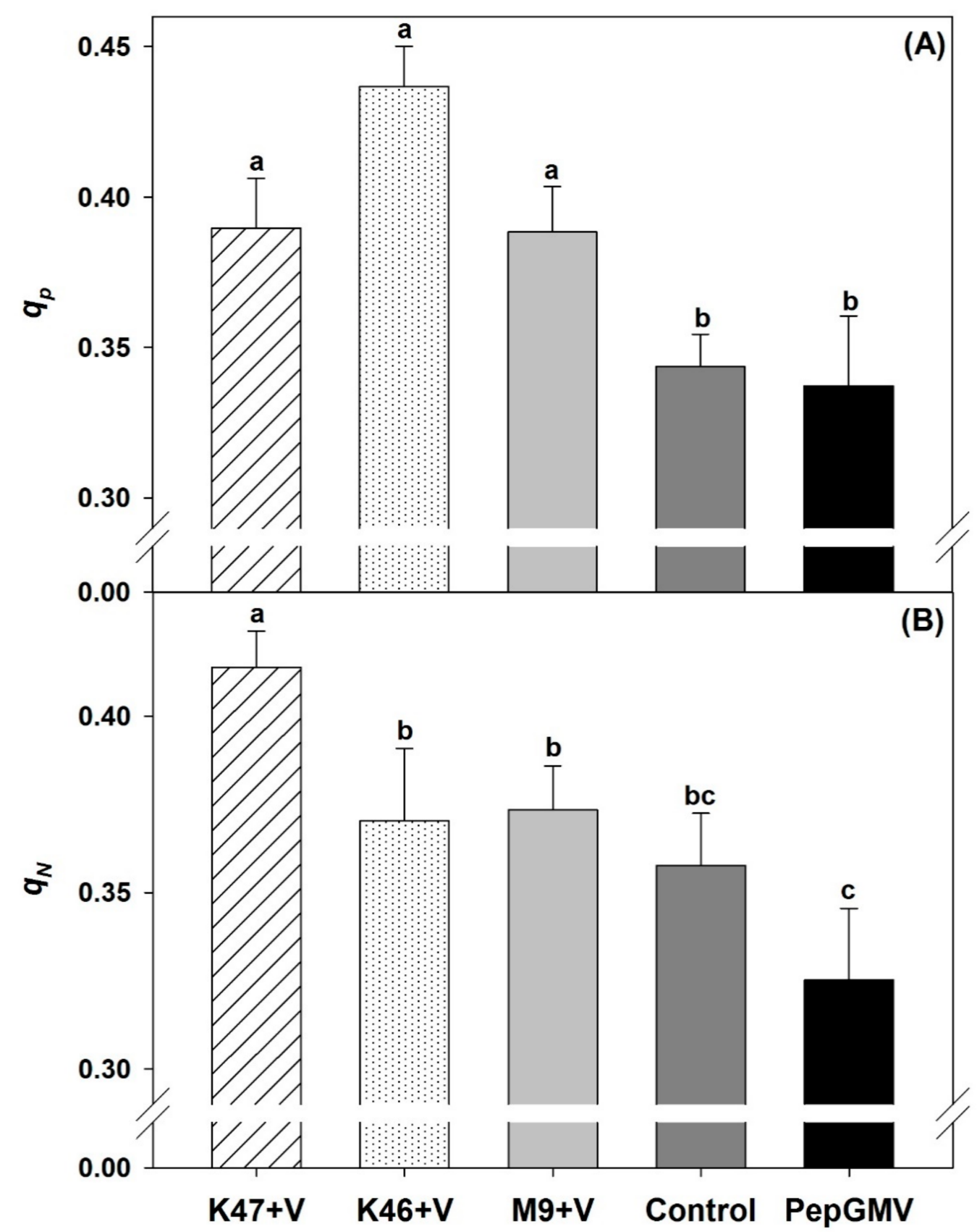

Figure 4. Photochemical quenching (A) and non-photochemical quenching (B) in Capsicum chinense plants infected with PepGMV and inoculated with Bacillus subtilis K47, B. cereus K46, Bacillus spp. M9; and plants infected with PepGMV not inoculated. Control = plants not inoculated with Bacillus spp. and not infected by PepGMV. Data are means \pm SE. Different letters represent statistically significant differences (Tukey, $\alpha=0.05, n=30$ ).

Inoculation with Bacillus spp. increased the $\mathrm{CO}_{2}$ assimilation in the treated plants compared to those that were uninoculated (Figure $5 \mathrm{~A}$ ). The $\mathrm{CO}_{2}$ assimilation rate in the plants inoculated with Bacillus and the control was statistically higher than in the 
PepGMV-infected plants (Figure 5A). Plants inoculated with Bacillus K47, K46, and M9 showed values increased by $22.10,26.31$, and $18.42 \%$ in comparison to virus-infected plants. However, nevertheless, plants inoculated with Bacillus spp. showed both decreased stomatal conductance (Figure 5B) and transpiration (Figure 5C) compared to the control plants. Additionally, the stomatal conductance and transpiration in plants inoculated with Bacillus spp. and the control plants were statistically higher than in the PepGMV-infected plants (Figure 5B,C). On the other hand, Bacillus K47, K46, and M9 enhanced the water use efficiency by $43.12,35.70$, and $43.52 \%$, respectively, compared to the PepGMV-infected plants (Figure 5D).

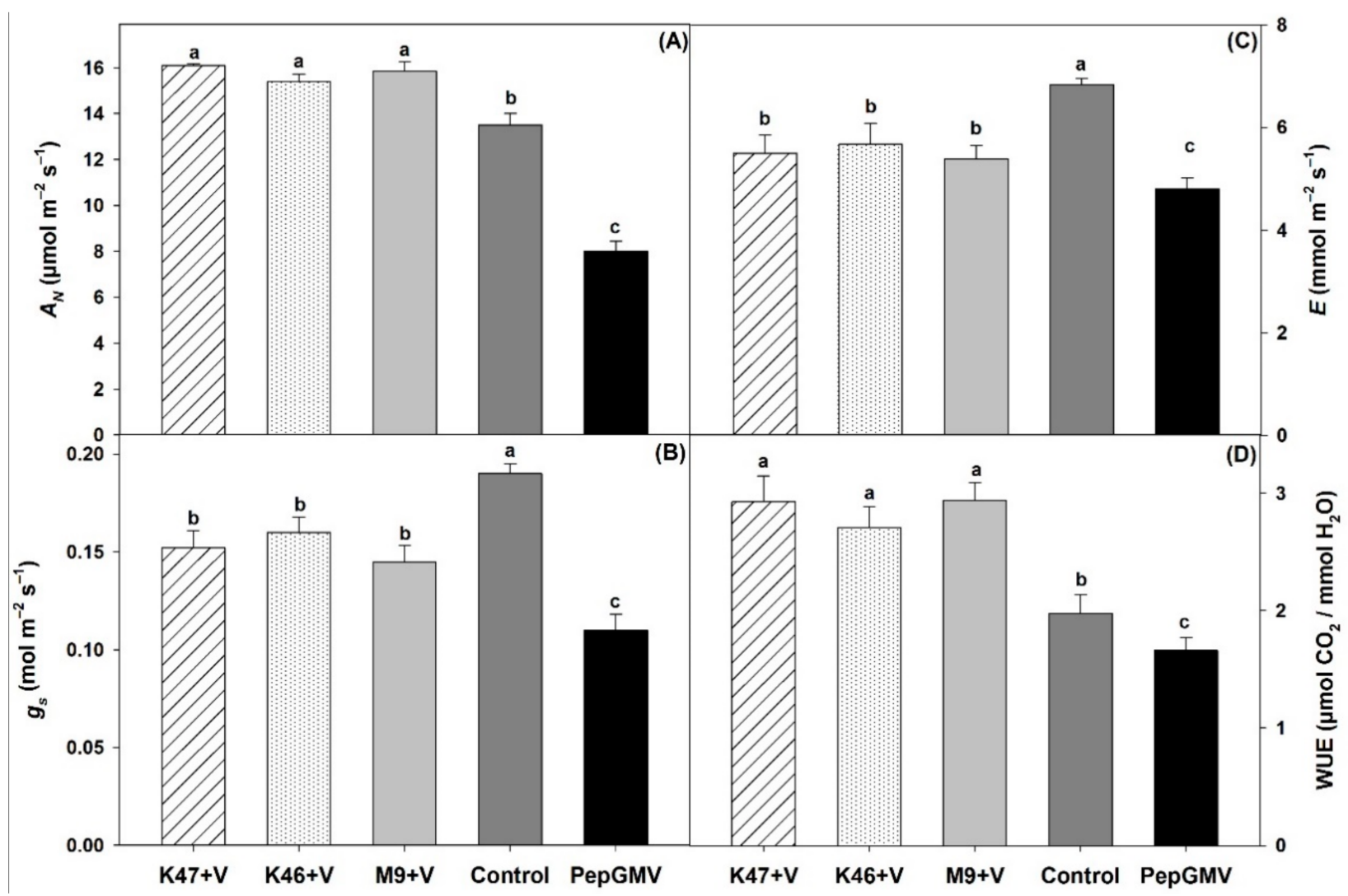

Figure 5. $\mathrm{CO}_{2}$ Assimilation rate (A), stomatal conductance (B), transpiration (C), and water use efficiency (D) in Capsicum chinense plants infected with PepGMV and inoculated with Bacillus subtilis K47, B. cereus K46, Bacillus spp. M9; and plants infected with PepGMV not inoculated. Control = plants not inoculated with bacteria and not infected by PepGMV. Data are means \pm SE. Different letters represent statistically significant differences (Tukey, $\alpha=0.05, n=30$ ).

\subsection{Yield of Plants with Bacillus spp.-C. chinense-PepGMV in Greenhouse}

Bacillus inoculation in seeds favored the greenhouse production of $C$. chinense infected with PepGMV (Table 2). Symptoms of PepGMV were observed 200 days after infection, with a lower severity shown in plants inoculated with the three Bacillus spp. The plants without the Bacillus inoculation showed more severe symptoms caused by PepGMV throughout the production cycle. Those with virus and Bacillus K46 or K47 showed the highest yields (Tukey, $\alpha=0.05$ ).

The yields of plants with rhizobacteria and the virus were statistically higher than those of plants that were not inoculated with Bacillus and the viral disease. Similarly, it was found that the fruits of plants with the Bacillus sp. K47-PepGMV treatment showed the highest weight. It was also observed that the plants inoculated with Bacillus spp. M9 and PepGMV or Bacillus sp. K46 and PepGMV produced fewer fruits per plant compared to both controls. However, the fruits produced were heavier than those of the control 
plants (Table 2). Plants inoculated with Bacillus spp. produced fruits whose weight was higher than that of uninoculated or PepGMV-inoculated plants (Table 2). This suggests that inoculation with Bacillus spp. sustained the plant performance and increased the fruit quality, despite the presence of PepGMV.

Table 2. Production of Habanero pepper (C. chinense) plants inoculated with Bacillus subtilis K47, B. cereus spp. K46, Bacillus sp. M9; plants infected with PepGMV; and PepGMV-infected plants. Control $=$ not inoculated with bacteria and not infected with PepGMV. Different letters represent statistically significant differences (Tukey, $\alpha=0.05, n=30$ ).

\begin{tabular}{cccc}
\hline Treatment & Fruits per Plant & Mean Fruit Weight (g) & Yield (g) per Plant \\
\hline K47 + PepGMV & $56 \pm 1.1^{\mathrm{a}}$ & $8.0 \pm 0.03^{\mathrm{a}}$ & $452 \pm 7.9^{\mathrm{a}}$ \\
K46 + PepGMV & $46 \pm 1.0^{\mathrm{c}}$ & $7.8 \pm 0.04^{\mathrm{b}}$ & $359 \pm 6.8^{\mathrm{b}}$ \\
M9 + PepGMV & $40 \pm 1.0^{\mathrm{d}}$ & $7.8 \pm 0.04^{\mathrm{b}}$ & $311 \pm 7.8^{\mathrm{c}, \mathrm{d}}$ \\
Control & $52 \pm 1.4^{\mathrm{b}}$ & $6.2 \pm 0.03^{\mathrm{c}}$ & $321 \pm 7.4^{\mathrm{c}}$ \\
PepGMV & $52 \pm 1.0^{\mathrm{b}}$ & $5.6 \pm 0.04^{\mathrm{d}}$ & $295 \pm 5.4^{\mathrm{d}}$ \\
\hline
\end{tabular}

\section{Discussion}

In this study, it was observed that biolistic inoculation caused symptoms such as golden mosaics, deformed leaves, and dwarfing in the plants grown in culture chambers. These symptoms have been observed in other studies using the same technique and PepGMV as a model $[3,26]$. However, in plants previously inoculated with different Bacillus isolates and infected with PepGMV, the disease severity was statistically lower when compared with plants without inoculation with rhizobacteria. At the symptom level, it was observed that plants inoculated with Bacillus spp. and infected with the virus showed a lower viral accumulation, incidence, and severity. Additionally, inoculated plants had a better photosynthetic performance. The mentioned could be attributed to a Bacillus-mediated ISR or viral replication inhibition or dilution due to increased plant growth $[27,28]$.

Investigations have evaluated the inoculation effect of Bacillus sp. in greenhouses and the open field, showing a reduction in the severity and incidence of other viral diseases at 28 and 40 dai with Tobacco mosaic virus (TMV), Tomato mottle virus (ToMoV), and Cucumber mosaic virus (CMV). The ISR induction was attributed to inoculation with Bacillus spp. $[27,29]$. In a study on CMV, it was observed that, during the second year of production, the disease incidence and severity levels were higher than in the first year. The reduced effectiveness of the rhizobacteria treatments was possibly caused by the increased levels of CMV naturally transmitted by aphids. Moreover, the plants may have been infected naturally with CMV isolates against which the Bacillus spp. used were not effective [30].

In our study, we observed at 200 dpi signs of wrinkling and light golden mosaics in plants previously inoculated with Bacillus K47, K46, and M9. However, plants inoculated with K47 showed a statistically low severity of PepGMV symptoms, with higher yields and fruit weight compared to inoculation with other Bacillus spp. isolates. This variability in the effect of inoculation with Bacillus spp. could depend on the bacteria isolates, the host plant, and the interactions with the pathogen used [11,21]. Furthermore, the induced resistance of the host may be influenced by its genotype and the environment [31].

Few data are available in the literature regarding the photosynthetic mechanisms involved in ISR during plant growth promoting rhizobacteria (PGPR) plant-virus interactions [22,32]. The plant physiological mechanisms affected by the diseases attributed to Begomovirus include the electron transport rate (ETR), the effective photochemical quantum yield of PSII ( $\Phi_{\text {PSII }}$ ), the maximum photochemical quantum yield of PSII (chlorophyll fluorescence: $\left.\mathrm{F}_{\mathrm{v}} / \mathrm{F}_{\mathrm{m}}\right)$, the potential activity of PSII $\left(\mathrm{F}_{\mathrm{v}} / \mathrm{F}_{0}\right)$, the $\mathrm{CO}_{2}$ assimilation rate (photosynthesis: $\left.A_{N}\right)$, the transpiration rate $(E)$, and the stomatal conductance $\left(g_{s}\right)[25,33]$.

Virus-infected plants reduce their photosynthetic rate due to a lower efficiency of PSII [34]. The presence of the virus capsid protein in chloroplasts causes an inhibition of PSII [35]. Tomato and cucumber plants infected with CMV and apricot plants infected 
with Pox plum virus (PPV) had decreased $\Phi_{\text {PSII }}[7,9]$. However, our results showed that, despite virus infection, the $C$. chinense plants inoculated with Bacillus spp. had a healthy photosynthetic mechanism, because both the photochemical (ETR, $\Phi_{\mathrm{PSII}}$, and $\mathrm{F}_{\mathrm{v}} / \mathrm{F}_{\mathrm{m}}$ ) and gas exchange $\left(\mathrm{A}_{\mathrm{N}}\right.$ and WUE) parameters increased.

It is known that some Bacillus increase photosynthesis activity to stimulate the production of endogenous sugars and regulate the plant energy acquisition, also stimulating the endogenous hormonal production (auxins, abscisic acid, jasmonic acid) [36,37]. A previous study in Habanero pepper plants inoculated with Bacillus spp. showed an increase in the overall photosynthetic capacity in vivo. Based on ETR, $\Phi_{\mathrm{PSII}}$, and $\mathrm{F}_{\mathrm{v}} / \mathrm{F}_{\mathrm{m}}$ data, it was suggested that inoculation with PGPR could prepare the plant for future abiotic stress situations [25]. However, according to our studies on photochemical parameters (ETR, $\Phi_{\mathrm{PSII}} \mathrm{m}$ and $\left.\mathrm{F}_{\mathrm{v}} / \mathrm{F}_{\mathrm{m}}\right)$, the inoculation with PGPR could prepare the plant for both abiotic and biotic stress situations. In this way, according to Li et al. [38], the electron transport rate is inhibited under stress conditions (i.e., there is a decrease in ATP and NADPH production). Moreover, it was suggested that a chlorophyll fluorescence $\left(\mathrm{F}_{\mathrm{v}} / \mathrm{F}_{\mathrm{m}}\right)$ value of around 0.83 is optimal for most plant species [39]. Thus, the improvement of Ethe TR and $F_{v} / F_{m}$ parameters appears related to the beneficial effect of the Bacillus spp. on PSII.

In addition, the results showed that $C$. chinense plants infected by PepGMV and inoculated with Bacillus spp. isolates increased the positive effects on the photosynthetic rates with respect to infected and control plants. In this way, it was reported that the size of stem cells decreased in tobacco plants infected with CMV. However, when infected plants were inoculated with Paenibacillus lentimorbus, the stem cells were in a turgid state [22]. Moreover, the bacteria-inoculated plants showed few structural anomalies in the leaf tissues and increased polyphenol accumulation in the hypodermis layer, extending to the collenchyma cells. The rhizobacteria-plant interaction also yields additional $\mathrm{CO}_{2}$ in the roots that can be transported to the shoot [40] for use in photosynthesis [41]. The Bacillus spp. used in this study likely produced endogenous sugars or $\mathrm{CO}_{2}$ from roots as a supply of carbon for photosynthesis from the vascular system and not from the stomata. The $\mathrm{CO}_{2}$ assimilation rate then increased and both the stomatal conductance and transpiration rate decreased, increasing the water use efficiency. Moreover, an increase in photosynthesis is a sign of surplus in carbon assimilates, thus photosynthate surplus is probably used in other metabolic pathways, such as polyphenols production, which could decrease the severity of disease symptoms.

According to the results, the seed inoculation with B. subtilis K47 kept the photosynthetic apparatus of the plant healthy during the disease progression, producing larger fruits when compared with those of healthy plants. The inoculation of Bacillus subtilis BEB-13bs in Lycopersicon esculentum Mill. favored the fruit quality by increasing the size and texture [42]. B. subtilis CAS15 reduced the incidence of Fusarium sp. in pepper [43], increasing the yield and fruit weight. The inoculation of B. amyloliquefaciens 5B6 in pepper leaves infected with CMV protected the infected plants that showed the same yield as healthy plants without rhizobacteria, suggesting an increase in ISR [44].

In this study, the inoculation with B. subtilis K47 decreased the viral disease severity and improved the yield, despite the PepGMV infection. During the interaction between Bacillus subtilis K47 and Capsicum chinense-PepGMV, the photosynthate surplus was likely used in the fruit production. On the other hand, it was observed that the M9 and K46 isolates had a different effect, as they did not improve the yield in plants but diminished the PepGMV severity.

Therefore, we suggest that inoculation with Bacillus spp. may likely promote ISR in plants infected with PepGMV, increasing the photosynthetic parameters and decreasing the viral disease severity, thus promoting a greater yield. These bacteria may thus be implemented in disease management programs in sustainable agriculture. 


\section{Materials and Methods}

\subsection{Plant Material and Growth Conditions}

The H-224 population [45] of Capsicum chinense was used, and the seeds were disinfected with sodium hypochlorite $(2 \%)$ and washed three times with sterile distilled water. Germination trays of 200 cavities filled with sterile peat moss substrate were moistened to field capacity with sterile distilled water. The seeds were then sown according to the experimental design. All trays were placed in a growth room at $25 \pm 2{ }^{\circ} \mathrm{C}$, with a photoperiod of 16/8 light/darkness, watered every second day, and leaf fertilized (UltraFol ${ }^{\mathrm{TM}}$, Biochem systems S.A. de C.V. Querétaro, Qro. México) weekly at a dose of $1 \mathrm{~g} \mathrm{~L}^{-1}$ distilled water. After 18 days of germination, the seedlings were transferred to Styrofoam cups ( $500 \mathrm{~mL}$ capacity filled with sterile peat moss substrate) and maintained in the same growth room under controlled conditions.

\subsection{Bacillus spp. Isolates and Inoculation}

Bacillus cereus K46, Bacillus M9 (a mixture of B. subtilis and B. amyloliquefaciens), and B. subtilis K47 were isolated from soil in the Yucatan Peninsula, Mexico. The growth of the isolates, the cell concentration $\left(10^{8}\right.$ cells $\mathrm{mL}^{-1}$ in $10 \mathrm{~mL}$ saline $\left.8 \%\right)$, and the inoculation were performed as previously described [25].

\subsection{Biolistic Infection}

Habanero pepper (C. chinense) seedlings obtained from seeds inoculated with the isolates described above, and having 3-4 true leaves (30 days after germination), were infected with PepGMV by biolistics. The third and fourth leaf above the inoculation point in C. chinense seedlings were biolistically inoculated at a $2 \mathrm{~cm}$ distance from the habanero pepper seedlings and at 100 to 120 psi helium pressure with $1 \mu \mathrm{m}$ gold particles (BioRad, Hercules, CA, USA) covered with $5 \mu \mathrm{g}$ of DNA from each of the A and B hemidimers of the PepGMV genome, as described previously [3]. The treatments were: (1) Bacillus subtilis (K47 isolated) + PepGMV; (2) Bacillus cereus (K46 isolate) + PepGMV; (3) Bacillus spp. (M9 isolates; a mixture of B. subtilis and B. amyloliquefaciens) + PepGMV; (4) uninoculated and noninfected plants (control); (5) plants infected with PepGMV. Each treatment consisted in one plant as experimental unit with 30 replicates. Plants with PepGMV were grown under controlled conditions $\left(25 \pm 2{ }^{\circ} \mathrm{C}\right.$, and photoperiod of $16 / 8$ light/darkness) for up to 28 days post infection (dpi) with PepGMV. At $28 \mathrm{dpi}$, the plants were transferred to black polyethylene bags (400 gauge) with a $5 \mathrm{~kg}$ capacity ( $35 \mathrm{~cm}$ diam. and $40 \mathrm{~cm}$ high) filled with sterile substrate and maintained in a greenhouse under controlled conditions $\left(30 \pm 2{ }^{\circ} \mathrm{C}, 65 \pm 3 \% \mathrm{HR}\right.$ and $1100 \mu$ moles luminous intensity).

\subsection{Virus Detection}

PepGMV infection in C. chinense plants was evaluated using $100 \mathrm{ng}$ of total DNA isolated from leaves from systemic infected individuals. The total DNA extraction was performed according to Doyle and Doyle [46] without modifications. The simples were treated with RNaseI and the DNA yield was measured spectrophotometrically (Nanodrop 2000, ThermoFisher). The PCR reactions were performed in a thermocycler (TC-412, Techne, Bibby Scientific Ltd., NJ, USA) with the following primers: 5-GCCTTGTGGAGAGCTAATGC-3 and 5- TTAGCGCAGTTGATGTGGAG-3 (213 bp) to target the AC2 gene. The PCR conditions were: 1 cycle at $94{ }^{\circ} \mathrm{C}(5 \mathrm{~min}) ; 35$ cycles at $94{ }^{\circ} \mathrm{C}(30 \mathrm{~s}), 58^{\circ} \mathrm{C}$ (30 s), and $72{ }^{\circ} \mathrm{C} \mathrm{(30} \mathrm{s);} \mathrm{and} \mathrm{a} \mathrm{final} \mathrm{extension} \mathrm{at} 72{ }^{\circ} \mathrm{C}(10 \mathrm{~min})$.

\subsection{Symptoms Severity}

The severity caused by PepGMV was evaluated at 9 and 15 dpi in a growth room under controlled conditions, and at $200 \mathrm{dpi}$ in a greenhouse. A four-level severity scale was modified and a methodology was used with values: 1: Golden mosaic; 2: Golden mosaic and leaf distortion; 3: Golden mosaic, leaf distortion, and chlorosis; 4: Golden mosaic, leaf distortion, chlorosis, and leaf curl; 5: Golden mosaic, general yellowing leaf 
distortion, chlorosis, and leaf curl. The severity of symptoms was calculated with a mean of ten observations per treatment [47].

\subsection{Chlorophyll Fluorescence and Gas Exchange Analysis}

The photochemical parameters of the leaves were measured with a portable pulse amplitude modulation fluorometer (PAM; Walz, Effeltrich, Germany) at pre-dawn (4:30 h) in plants 140 days after sowing. The light response curves of both the relative electron transport rate $\left(\mathrm{ETR}_{\mathrm{PSII}}\right)$ and the effective photochemical quantum yield $\left(\Phi_{\mathrm{PSII}}\right)$ of PSII were obtained with actinic irradiance (PPFD) from 0 to $1500 \mu \mathrm{mol}$ photons $\mathrm{m}^{-2} \mathrm{~s}^{-1}$. Both the maximum photochemical quantum yield of photosystem II $\left(\mathrm{F}_{\mathrm{v}} / \mathrm{F}_{\mathrm{m}}\right)$ and the potential activity of PSII $\left(\mathrm{F}_{\mathrm{v}} / \mathrm{F}_{0}\right)$ were measured: $\mathrm{F}_{\mathrm{v}}=$ variable fluorescence $\left(\mathrm{F}_{\mathrm{m}}-\mathrm{F}_{0}\right), \mathrm{F}_{0}=$ initial fluorescence, and $\mathrm{F}_{\mathrm{m}}$ maximum fluorescence. A saturating pulse once every $20 \mathrm{~s}$ was applied to obtain the steady-state fluorescence, as well was photochemical fluorescence quenching $(\mathrm{qP})$. All the calculated parameters and light characteristics used in the fluorometer (saturation pulse intensity, pulse length, and light intensity) were as described [25]. Gas exchange analyses were carried out under greenhouse conditions (average temperature: $28^{\circ} \mathrm{C}$ during the day and $24^{\circ} \mathrm{C}$ during the night; photosynthetic active radiation: $1200 \mu \mathrm{mol}$ photons $\mathrm{m}^{-2} \mathrm{~s}^{-1}$ at noon; average HR: 65\%) using a portable infrared gas analyzer system (IRGA; LICOR, LI-6400, Nebraska, USA). Fifteen fully expanded young leaves from each treatment were placed in the IRGA gas-exchange leaf chamber. The $\mathrm{CO}_{2}$ assimilation rate $\left(A_{N}\right)$, stomatal conductance $\left(g_{s}\right)$, transpiration $(E)$, and water use efficiency (WUE) were measured as described [48].

\subsection{Agronomic Parameters}

For the evaluation of the yield and fruit characteristics, the harvest was started from week 12 after transplanting to the greenhouse (datg). A harvest was carried out every seven days (week 12,13, and 14 datg), and the completely ripe fruit (orange) per plant were weighed and quantified per harvest (three harvests in total).

\subsection{Experimental Design and Statistical Analysis}

The experiments were performed in a completely randomized design. The photosynthetic, gas exchange, and agronomic parameters were examined through ANOVA and the means of each treatment were compared with Tukey's HSD test at $p \leq 0.05$ (Statistic Six Sigma, Release 7, StatSoft).

Author Contributions: Conceptualization: B.Y.S.-G., J.M.T.-S., and R.G.; methodology: R.E.V.-G., O.A.M.-V., A.R.-R., and R.G.; software: R.E.V.-G. and R.G.; validation: C.E.A.-C. and L.T.-P.; formal analysis: B.Y.S.-G.; investigation: B.Y.S.-G.; resources: J.M.T.-S., R.G. and O.A.M.-V.; writing-original draft preparation: B.Y.S.-G. and R.G.; writing-review and editing: R.E.V.-G.; Funding acquisition: J.M.T.-S. All authors have read and agreed to the published version of the manuscript.

Funding: This research received no external funding.

Institutional Review Board Statement: Not applicable.

Informed Consent Statement: Not applicable.

Data Availability Statement: Not applicable.

Acknowledgments: The authors thank Rafael Rivera-Bustamante for donating the infective clone of PepGMV, and Jorge Kantun-Can for his support in the field experiments.

Conflicts of Interest: The authors declare no conflict of interest. 


\section{References}

1. Acosta-Leal, R.; Duffy, S.; Xiong, Z.; Hammond, R.W.; Elena, S.F. Advances in plant virus evolution: Translating evolutionary insights into better disease management. Phytopathology 2011, 101, 1136-1148. [CrossRef] [PubMed]

2. Mejía-Teniente, L.M.; Joaquín-Ramos, A.J.; Torres-Pacheco, I.; Rivera-Bustamante, R.F.; Guevara-Olvera, L.; Rico-García, E.; Guevara-Gonzalez, R.G. Silencing of a Germin-Like Protein Gene (CchGLP) in Geminivirus-Resistant Pepper (Capsicum chinense Jacq.) BG-3821 Increases Susceptibility to Single and Mixed Infections by Geminiviruses PHYVV and PepGMV. Viruses 2015, 7, 6141-6151. [CrossRef] [PubMed]

3. Carrillo-Tripp, J.; Lozoya-Gloria, E.; Rivera-Bustamante, R.F. Symptom remission and specific resistance of pepper plants after infection by Pepper golden mosaic virus. Phytopathology 2007, 97, 51-59. [CrossRef] [PubMed]

4. Trejo-Saavedra, D.L.; García-Neria, M.A.; Rivera-Bustamante, R.F. Benzothiadiazole (BTH) induces resistance to Pepper golden mosaic virus (PepGMV) in pepper (Capsicum Annu. L.). Biol. Res. 2013, 46, 333-340. [CrossRef]

5. Rahoutei, J.; García-Luque, I.; Barón, M. Inhibition of photosynthesis by viral infection: Effect on PSII structure and function. Physiol. Plant. 2000, 110, 286-292. [CrossRef]

6. Kokkinos, C.D.; Clark, C.A.; McGregor, C.E.; LaBonte, D.R. The Effect of Sweet Potato Virus Disease and its Viral Components on Gene Expression Levels in Sweetpotato. J. Am. Soc. Hortic. Sci. 2006, 131, 657-666. [CrossRef]

7. Song, X.S.; Wang, Y.J.; Mao, W.H.; Shi, K.; Zhou, Y.H.; Nogués, S.; Yu, J.Q. Effects of Cucumber mosaic virus infection on electron transport and antioxidant system in chloroplasts and mitochondria of cucumber and tomato leaves. Physiol. Plant. 2009, 135, 246-257. [CrossRef]

8. Hernández, J.A.; Díaz-Vivancos, P.; Rubio, M.; Olmos, E.; Ros-Barceló, A.; Martínez-Gómez, P. Long-term Plum pox virus infection produces an oxidative stress in a susceptible apricot, Prunus armeniaca, cultivar but not in a resistant cultivar. Physiol. Plant. 2006, 126, 140-152. [CrossRef]

9. Díaz-Vivancos, P.; Clemente-Moreno, M.J.; Rubio, M.; Olmos, E.; García, J.A.; Martínez-Gómez, P.; Hernández, J.A. Alteration in the chloroplastic metabolism leads to ROS accumulation in pea plants in response to Plum pox virus. J. Exp. Bot. 2008, 59, 2147-2160. [CrossRef]

10. Pérez-Bueno, M.L.; Rahoutei, J.; Sajnani, C.; García-Luque, I.; Barón, M. Proteomic analysis of the oxygen-evolving complex of photosystem II under biotec stress: Studies on Nicotiana benthamiana infected with tobamoviruses. Proteomics 2004, 4, 418-425. [CrossRef]

11. Choudhary, D.K.; Johri, B.N. Interactions of Bacillus spp. and plants—With special reference to induced systemic resistance (ISR). Microbiol. Res. 2009, 164, 493-513. [CrossRef]

12. Beneduzi, A.; Ambrosini, A.; Passaglia, L.M.P. Plant growth-promoting rhizobacteria (PGPR): Their potential as antagonists and biocontrol agents. Genet. Mol. Biol. 2012, 35, 1044-1051. [CrossRef]

13. Domenech, J.; Ramos, S.B.; Probanza, A.; Lucas, G.J.A.; Gutiérrez, M.F.J. Elicitation of systemic resistance and growth promotion of Arabidopsis thaliana by PGPRs from Nicotiana glauca: A study of the putative induction pathway. Plant Soil 2007, 290, 43-50. [CrossRef]

14. Mehta, P.; Walia, A.; Kulshrestha, S.; Chauhan, A.; Shirkot, C.K. Efficiency of plant growth-promoting P-solubilizing Bacillus circulans CB7 for enhancement of tomato growth under net house conditions. J. Basic Microb. 2015, 55, 33-44. [CrossRef]

15. Kang, S.M.; Radhakrishnan, R.; You, Y.H.; Joo, G.J.; Lee, I.J.; Lee, K.E.; Kim, J.H. Phosphate Solubilizing Bacillus megaterium mj1212 Regulates Endogenous Plant Carbohydrates and Amino Acids Contents to Promote Mustard Plant Growth. Indian J. Microbiol. 2014, 54, 427-433. [CrossRef]

16. Talboys, P.J.; Owen, D.W.; Healey, J.R.; Withers, P.J.A.; Jones, D.L. Auxin secretion by Bacillus amyloliquefaciens FZB42 both stimulates root exudation and limits phosphorus uptake in Triticum aestivum. BMC Plant Biol. 2014, 14, 51. [CrossRef]

17. Hanif, M.K.; Hameed, S.; Imran, A.; Naqqash, T.; Shahid, M.; Van Elsas, J.D. Isolation and characterization of a $\beta$-propeller gene containing phosphobacterium Bacillus subtilis strain KPS-11 for growth promotion of potato (Solanum tuberosum L.). Front. Microbiol. 2015, 6, 583. [CrossRef]

18. Shao, J.; Xu, Z.; Zhang, N.; Shen, Q.; Zhang, R. Contribution of indole-3-acetic acid in the plant growth promotion by the rhizospheric strain Bacillus amyloliquefaciens SQR9. Biol. Fertil. Soils 2015, 51, 321-330. [CrossRef]

19. Ruíz-Sánchez, E.; Mejía-Bautista, M.A.; Serrato-Díaz, A.; Reyes-Ramírez, A.; Estrada-Girón, Y.; Valencia-Botín, A.J. Antifungal activity and molecular identification of native strains of Bacillus subtilis. Agrociencia 2016, 50, 133-148.

20. Samaniego-Gámez, B.Y.; Reyes-Ramírez, A.; Moreno-Valenzuela, O.A.; Tun-Suárez, J.M. Resistencia sistémica inducida contra virus fitopatógenos mediada por la inoculación con la rizobacteria Bacillus spp. Rev. Prot. Veg. 2017, 32, 10-22.

21. Kloepper, J.W.; Ryu, C.M.; Zhang, S. Induced systemic resistance and promotion of plant growth by Bacillus spp. Phytopathology 2004, 94, 1259-1266. [CrossRef]

22. Kumar, S.; Chauhan, P.S.; Agrawal, L.; Raj, R.; Srivastava, A.; Gupta, S.; Mishra, S.K.; Yadav, S.; Singh, P.C.; Raj, S.K.; et al. Paenibacillus lentimorbus Inoculation Enhances Tobacco Growth and Extenuates the Virulence of Cucumber mosaic virus. PLoS ONE 2016, 11, e0149980. [CrossRef] [PubMed]

23. Kanchana, D.; Jayanthi, M.; Usharani, G.; Saranraj, P.; Sujitha, D. Interaction effect of combined inoculation of PGPR on growth and yield parameters of Chilli Var K1 (Capsicum annuum L.). Int. J. Microbiol. Res. 2014, 5, 144-151. 
24. Gan, H.Y.; Gan, H.M.; Savka, M.A.; Triassi, A.J.; Wheatley, M.S.; Naqvi, K.F.; Foxhall, T.E.; Anauo, M.J.; Baldwin, M.L.; Burkhardt, R.N.; et al. Whole-genome sequencing and annotation of Bacillus safensis RIT372 and Pseudomonas oryzihabitans RIT370 from Capsicum annuum (bird's eye chili) and Capsicum chinense (yellow lantern chili), respectively. Genome Announc. 2015, 3, e00288-15. [CrossRef] [PubMed]

25. Samaniego-Gámez, B.Y.; Garruña, R.; Tun-Suárez, J.M.; Kantun-Can, J.; Reyes-Ramírez, A.; Cervantes-Díaz, L. Bacillus spp. inoculation improves photosystem II efficiency and enhances photosynthesis in pepper plants. Chil. J. Agric. Res. 2016, 76, 409-416. [CrossRef]

26. Ceniceros-Ojeda, E.A.; Rodríguez-Negrete, E.A.; Rivera-Bustamante, R.F. Two populations of viral minichromosomes are present in a geminivirus-infected plant showing symptom remission (recovery). J. Virol. 2016, 90, 3828-3838. [CrossRef] [PubMed]

27. Choi, H.K.; Song, G.C.; Yi, H.S.; Ryu, C.M. Field evaluation of the bacterial volatile derivative 3-pentanol in priming for induced resistance in pepper. J. Chem. Ecol. 2014, 40, 882-892. [CrossRef] [PubMed]

28. Elbeshehy, E.K.F.; Youssef, S.A.; Elazzazy, A.M. Resistance induction in pumpkin Cucurbita maxima L. against Watermelon mosaic potyvirus by plant growth-promoting rhizobacteria. BioControl Sci. Technol. 2015, 25, 525-542. [CrossRef]

29. Wang, S.; Wu, H.; Qiao, J.; Ma, L.; Liu, J.; Xia, Y.; Gao, X. Molecular Mechanism of Plant Growth Promotion and Induced Systemic Resistance to Tobacco mosaic virus by Bacillus spp. J. Microbiol. Biotechnol. 2009, 9, 1250-1258. [CrossRef]

30. Zehnder, G.W.; Yao, C.; Murphy, J.F.; Sikora, E.R.; Kloepper, J.W. Induction of resistance in tomato against Cucumber mosaic cucumovirus by plant growth-promoting rhizobacteria. BioControl 2000, 45, 127-137. [CrossRef]

31. Faoro, F.; Gozzo, F. Is modulating virus virulence by induced systemic resistance realistic? Plant Sci. 2015, 234, 1-13. [CrossRef]

32. Zamioudis, C.; Korteland, J.; Van Pelt, J.A.; van Hamersveld, M.; Dombrowski, N.; Bai, Y.; Hanson, J.; Van Verk, M.C.; Ling, H.Q.; Schulze-Lefert, P.; et al. Rhizobacterial volatiles and photosynthesis-related signals coordinate MYB72 expression in Arabidopsis roots during onset of induced systemic resistance and iron-deficiency responses. Plant J. 2015, 84, 309-322. [CrossRef]

33. Tajul, M.I.; Naher, K.; Hossain, T.; Siddiqui, Y.; Sariah, M. Tomato yellow leaf curl virus (TYLCV) alters the phytochemical constituents in tomato fruits. Aust. J. Crop. Sci. 2011, 5, 575-581.

34. Bertamini, M.; Muthuchelain, K.; Nedunchezhian, N. Effect of Grapevine Leafroll on the Photosynthesis of Field Grown Grapevine Plants (Vitis vinifera L. cv. Lagrein). J. Phytopathol. 2004, 152, 145-152. [CrossRef]

35. Abbink, T.E.M.; Peart, J.R.; Mos, T.N.M.; Baulcombe, D.C.; Bol, J.F.; Linthors, H.J.M. Silencing of a gene encoding a protein component of the oxygen-evolving complex of photosystem II enhances virus replication in plants. Virology 2002, 295, 307-319. [CrossRef]

36. Patten, C.L.; Glick, B.R. Bacterial biosynthesis of indole-3-acetic acid. Can. J. Microbiol. 1996, 42, 207-220. [CrossRef]

37. Zhang, H.; Xie, X.; Kim, M.S.; Kornyeyev, D.A.; Holaday, S.; Pare, P.W. Soil bacteria augment Arabidopsis photosynthesis by decreasing glucose sensing and abscisic acid level in planta. Plant J. 2008, 56, 264-273. [CrossRef]

38. Li, W.; Zhang, S.; Shan, L. Responsibility of non-stomatal limitations for the reduction of photosynthesis-response of photosynthesis and antioxidant enzyme characteristics in alfalfa (Medicago sativa L.) seedlings to water stress and rehydration. Front. Agric. China 2007, 1, 255-264. [CrossRef]

39. Maxwell, K.; Johnson, G.N. Chlorophyll flouresence-A practical guide. J. Exp. Bot. 2000, 51, 659-668. [CrossRef]

40. Hibberd, J.M.; Quick, W.P. Characteristics of C-4 photosynthesis in stems and petioles of C-3 flowering plants. Nature 2002, 415, 451-454. [CrossRef]

41. Rozpadek, P.; Wężowicz, K.; Nosek, M.; Ważny, R.; Tokarz, K.; Lembicz, M.; Miszalski, Z.; Turnau, K. The fungal endophyte Epichloë typhina improves photosynthesis efficiency of its host orchard grass (Dactylis glomerata). Planta 2015, 242, 1025-1035. [CrossRef] [PubMed]

42. Mena-Violante, H.G.; Olalde-Portugal, V. Alteration of tomato fruit quality by root inoculation with plant growth-promoting rhizobacteria (PGPR): Bacillus subtilis BEB-13bs. Sci. Hortic. 2007, 113, 103-106. [CrossRef]

43. Yu, X.; Ai, C.; Xin, L.; Zhou, G. The siderophore-producing bacterium, Bacillus subtilis CAS15, has a biocontrol effect on Fusarium wilt and promotes the growth of pepper. Eur. J. Soil Biol. 2011, 47, 138-145. [CrossRef]

44. Lee, G.H.; Ryu, C.M. Spraying of leaf-colonizing Bacillus amyloliquefaciens protects pepper from Cucumber mosaic virus. Plant Dis. 2016, 100, 2099-2105. [CrossRef] [PubMed]

45. Latournerie-Moreno, L.; Lopez-Vázquez, J.S.; Castañón-Nájera, G.; Mijangos-Cortéz, J.O.; Espadas-Villamil, G.; Pérez-Gutiérrez, A.; Ruiz-Sánchez, E. Evaluación agronómica de germoplasma de chile habanero (Capsicum chinense Jacq.). Agroproductividad 2015, $1,24-29$.

46. Doyle, J.J.; Doyle, J.L. Isolation of plant DNA from fresh tissue. BRL Focus 1990, 12, 13-15.

47. Anaya-López, J.L.; Torres-Pacheco, I.; González-Chavira, M.; Garzon-Tiznado, J.A.; Pons-Hernandez, J.L.; Guevara-González, R.G.; Muñoz-Sánchez, C.I.; Guevara-Olvera, L.; Rivera-Bustamante, R.F.; Hernández-Verdugo, S. Resistance to Geminivirus Mixed Infections in Mexican Wild Peppers. HortScience 2003, 38, 251-255. [CrossRef]

48. Garruña-Hernández, R.; Orellana, R.; Larque-Saavedra, A.; Canto, A. Understanding the physiological responses of a tropical crop (Capsicum chinense Jacq.) at high temperature. PLoS ONE 2014, 9, e111402. [CrossRef] 